\title{
Tranexamic acid: less bleeding and less thrombosis?
}

Anne Godier ${ }^{1,2}$, Ian Roberts ${ }^{3}$ and Beverley J Hunt ${ }^{2,4,5, *}$

\begin{abstract}
The early administration of tranexamic acid (TXA) to bleeding trauma patients reduces all-cause mortality without increasing the risk of vascular occlusive events. Indeed, the risk of arterial thrombosis appears to be reduced with TXA. In this commentary we hypothesize that TXA has an antithrombotic effect and explore potential mechanisms. These include inhibition of the inflammatory effects of plasmin, effects on platelets and effects on factors $V$ and VIII. If proven, these antithrombotic effects would have major implications for the systemic use of TXA in surgical patients, where TXA has been clearly shown to reduce bleeding.
\end{abstract}

\section{Introduction}

The antifibrinolytic agent tranexamic acid (TXA) has been shown to reduce bleeding in elective surgery. A recent systematic review of randomised controlled trials shows that TXA reduces the probability of receiving a blood transfusion by nearly $40 \%$ [1]. There was also a non-significant reduction in the risk of myocardial infarction (MI) with TXA (relative risk $(\mathrm{RR})=0.68,95 \%$ confidence interval (CI) 0.43 to $1.09 ; P=0.11$ ).

The CRASH-2 (Clinical Randomisation of an Antifibrinolytic in Significant Haemorrhage 2) trial of TXA in bleeding trauma patients was motivated by the evidence that TXA reduces surgical bleeding and the knowledge that the haemostatic responses to trauma and surgery share common features. The results showed a significant reduction in death due to bleeding and allcause mortality with TXA [2]. The reduction was largest for those treated soon after injury [2]. TXA treatment within 3 hours of injury reduced the risk of death due to bleeding by nearly $30 \%$. Moreover, there were fewer vascular occlusive deaths with TXA $(\mathrm{RR}=0.69,95 \% \mathrm{CI}$

*Correspondence: Beverley.Hunt@gstt.nhs.uk

${ }^{5}$ St Thomas' Hospital, Westminster Bridge Road, London, SE1 7EH, UK

Full list of author information is available at the end of the article
0.44 to $1.07 ; P=0.096)$ and a significant reduction in fatal and non-fatal MI (RR $=0.64,95 \%$ CI 0.42 to 0.97 ; $P=0.035$ ). We hypothesize that TXA may have an antithrombotic effect and explore the possible mechanisms.

The reduction in MI could be due to the anti-inflammatory effects of TXA. Trauma and surgery are known to generate a systemic inflammatory response, characterized by systemic activation of fibrinolysis, coagulation, complement, platelets, and oxidative pathways $[3,4]$. This inflammation is associated with increased risk of thrombosis. While a causal role for chronic inflammation in atherosclerotic disease is well established, evidence that acute inflammation may promote vascular events is accumulating, with increases in risk after infection [5] and surgery [6].

TXA has anti-inflammatory effects. It is a synthetic derivative of the amino acid lysine that blocks the lysine binding sites of plasminogen and plasmin, inhibiting their effects, including their fibrinolytic and inflammatory effects. Plasminogen binds not only to fibrin, causing fibrinolysis, but also to receptors on cells involved in the inflammation process, such as monocytes, macrophages, neutrophils, endothelial cells and platelets. Plasminogen receptors include the annexin A2-S100A10 heterotetramer, $\alpha$-enolase, histone $\mathrm{H} 2 \mathrm{~B}$ and the transmembrane plasminogen receptor Plg-R(KT). The binding of plasminogen to these receptors initiates inflammatory processes. For example, the binding to annexin A2 increases the expression and release of a major chemokine called monocyte-macrophage chemo-attractant protein (MCP-1) [7]. The binding to $\alpha$-enolase is involved in monocyte recruitment in inflammatory lung disease [8]. Plg-R(KT) is a plasminogen receptor that is co-localized on the monocyte surface with the urokinase receptor (UPAR) and interacts directly with tissue plasminogen activator [9]. Plg- $R(K T)$ is believed to play a role in plasminogendependent regulation of macrophage migration, invasion, and recruitment in the inflammatory response. In summary, after binding to its receptors, plasminogen has a range of potent pro-inflammatory effects, which may be inhibited by TXA.

Once activated, plasmin can stimulate lipid mediator release, increase the biosynthesis of leucotrienes, 
promote cytokine release and induce the expression of some inflammatory genes. Plasmin also causes degradation of extracellular matrix components, thus facilitating chemotaxis and inflammatory cell migration across adhesive substrates. Plasmin also activates inflammatory signalling networks, leading to phosphorylation and activation of the p38 mitogen-activated protein kinase (MAPK) and JAK/STAT signalling pathways [10]. By blocking the binding sites of plasminogen and plasmin, TXA could inhibit these inflammatory effects. A randomised controlled trial of TXA in patients undergoing cardiopulmonary bypass showed that perioperative TXA reduced the inflammatory response and vasoplegic shock [4].

TXA may also reduce thrombotic events via effects on platelets and coagulation proteins. There is some evidence that plasmin can cause platelet activation. This was clinically noted in the early trials of thrombolysis in myocardial infarction where fibrinolytic (plasmin) activators were used initially without anti-platelet agents. Reocclusion occurred in approximately $20 \%$ of cases after stopping fibrinolytic agents [11]. However, the use of anti-platelet drugs prevented re-occlusion. Plasmin may mediate platelet aggregation through proteolytic cleavage of a thrombin receptor, protease-activated receptor 4 (PAR4) [12]. Other anti-platelet mechanisms have been suggested. Plasmin is believed to cause platelet aggregation by stimulating platelet degranulation and release of both dense granules, with ADP, and alpha granules, with fibrinogen and von Willebrand factor, which lead to the activation, recruitment, and aggregation of platelets. Plasmin also stimulates the arachidonic acid cascade, which leads to activation of prostacyclin biosynthesis and, hence, platelet activation. Finally, plasmin may cause platelet aggregation by complement activation [13].

Plasmin also has a role in coagulation. At high concentrations, plasmin has procoagulant effects. Plasmin proteolyses coagulation factors but has a unique biphasic effect on factors V and VIII: proteolytic breakdown is preceded by a brief burst of activation $[14,15]$. Incubation of factor V or VIII with plasmin results in a rapid increase in procoagulant activity, factor VIII levels increase twofold within 3 minutes and then are undetectable within 45 minutes [16]. This brief activation may generate enough thrombin to produce a significant procoagulant effect. Another procoagulant effect of plasmin is that it causes proteolytic breakdown of a physiological anticoagulant, tissue factor protein inhibitor, a major inhibitor of tissue factor-mediated coagulation [17], and these changes are abolished by antifibrinolytic agents [18].

\section{Conclusion}

Plasminogen and plasmin have a wide range of potential pro-thrombotic effects. The reduction in MI observed with TXA in the CRASH-2 trial is compatible with a significant antithrombotic effect of TXA. This effect may be mediated via its impact on inflammation, platelet effects or coagulation factors. However, the data are limited and more in vitro and clinical studies are required.

If TXA reduces the need for blood transfusion and reduces the risk of thrombosis, this would have major implications for surgical patients. Every year, world-wide, between 500,000 and 900,000 patients experience perioperative cardiac death, non-fatal MI or non-fatal cardiac arrest [19]. If the effect of TXA on the risk of arterial thrombotic events seen in trauma also applies in surgery, TXA might prevent hundreds of thousands of cardiac events. Because thrombotic events are uncommon, small trials lack power and a meta-analysis of small trials would be vulnerable to publication bias. For this reason a large pragmatic trial of TXA administration in surgical patients is needed. The possibility that TXA could reduce surgical morbidity and mortality through a reduction in perioperative bleeding and postoperative thrombosis justifies the effort involved.

\section{Abbreviations}

$\mathrm{Cl}$, confidence interval; CRASH-2, Clinical Randomisation of an Antifibrinolytic in Significant Haemorrhage 2; Ml, myocardial infarction; RR, relative risk; TXA, tranexamic acid.

\section{Competing interests}

The authors declare that they have no competing interests.

\section{Acknowledgements}

This paper was supported by a grant from the Société Française d'Anesthésie Réanimation.

\section{Authors' contributions}

$A G, I R$ and $B H$ wrote the manuscript. The final version was approved by all authors.

\section{Author details}

'Department of Anesthesia and Critical Care, Hotel-Dieu and Cochin Hospitals, Paris Descartes University, 75004, Paris, France. ²Department of Thrombosis and Vascular Biology, Rayne Institute, 4th Floor, Lambeth Wing, St. Thomas' Hospital, Westminster Bridge Road, London SE1 7EH, UK. ${ }^{3}$ Clinical Trials Unit, London School of Hygiene and Tropical Medicine, Keppel Street, London WC1E 7HT, UK. ${ }^{4 T h r o m b o s i s ~ a n d ~ H a e m o s t a s i s ~ C e n t r e, ~ G u y ' s ~ a n d ~ S t ~ T h o m a s ' s ~}$ NHS Foundation Trusts, and King's College, London, SE1 7EH, UK. 'SSt Thomas' Hospital, Westminster Bridge Road, London, SE1 7EH, UK.

Published: 29 June 2012

\section{References}

1. Ker K, Edwards P, Perel P, Shakur H, Roberts I: Effect of tranexamic acid on surgical bleeding: systematic review and cumulative meta-analysis. BMJ 2012, 344:e3054

2. CRASH-2 collaborators, Roberts I, Shakur H, Afolabi A, Brohi K, Coats T, Dewan Y, Gando S, Guyatt G, Hunt BJ, Morales C, Perel P, Prieto-Merino D, Woolley T: The importance of early treatment with tranexamic acid in bleeding trauma patients: an exploratory analysis of the CRASH-2 randomised controlled trial. Lancet 2011, 377:1096-1101, 1101.e1-2.

3. Brohi K, Cohen MJ, Ganter MT, Schultz MJ, Levi M, Mackersie RC, Pittet JF: Acute coagulopathy of trauma: hypoperfusion induces systemic anticoagulation and hyperfibrinolysis. J Trauma 2008, 64:1211-1217; discussion 1217. 
4. Jimenez JJ, Iribarren JL, Lorente L, Rodriguez JM, Hernandez D, Nassar I, Perez R, Brouard M, Milena A, Martinez R, Mora ML: Tranexamic acid attenuates inflammatory response in cardiopulmonary bypass surgery through blockade of fibrinolysis: a case control study followed by a randomized double-blind controlled trial. Crit Care 2007, 11:R117.

5. Smeeth L, Thomas SL, Hall AJ, Hubbard R, Farrington P, Vallance P: Risk of myocardial infarction and stroke after acute infection or vaccination. N Engl J Med 2004, 351:2611-2618.

6. Ng J, Chan MT, Gelb AW: Perioperative stroke in noncardiac nonneurosurgical surgery. Anesthesiology 2011, 115:879-890.

7. Laumonnier $Y$, Syrovets T, Burysek L, Simmet T: Identification of the annexin A2 heterotetramer as a receptor for the plasmin-induced signaling in human peripheral monocytes. Blood 2006, 107:3342-3349.

8. Wygrecka M, Marsh LM, Morty RE, Henneke I, Guenther A, Lohmeyer J, Markart P, Preissner KT: Enolase-1 promotes plasminogen-mediated recruitment of monocytes to the acutely inflamed lung. Blood 2009, 113:5588-5598.

9. Lighvani S, Baik N, Diggs JE, Khaldoyanidi S, Parmer RJ, Miles LA: Regulation of macrophage migration by a novel plasminogen receptor Plg-R KT. Blood 2011, 118:5622-5630.

10. Burysek L, Syrovets $T$, Simmet $T$ : The serine protease plasmin triggers expression of MCP-1 and CD40 in human primary monocytes via activation of p38 MAPK and janus kinase (JAK)/STAT signaling pathways. J Biol Chem 2002, 277:33509-33517.

11. Chesebro JH, Knatterud G, Roberts R, Borer J, Cohen LS, Dalen J, Dodge HT, Francis CK, Hillis D, Ludbrook P, et al:: Thrombolysis in Myocardial Infarction (TIMI) Trial, Phase I: A comparison between intravenous tissue plasminogen activator and intravenous streptokinase. Clinical findings through hospital discharge. Circulation 1987, 76:142-154.

12. Quinton TM, Kim S, Derian CK, Jin J, Kunapuli SP: Plasmin-mediated activation of platelets occurs by cleavage of protease-activated receptor 4. J Biol Chem 2004, 279:18434-18439.

13. Amara U, Flierl MA, Rittirsch D, Klos A, Chen H, Acker B, Brückner UB, Nilsson B, Gebhard F, Lambris JD, Huber-Lang M: Molecular intercommunication between the complement and coagulation systems. J Immuno/ 2010, 185:5628-5636.

14. Ogiwara K, Nogami K, Nishiya K, Shima M: Plasmin-induced procoagulant effects in the blood coagulation: a crucial role of coagulation factors $V$ and VIII. Blood Coagul Fibrinolysis 2010, 21:568-576.

15. Lee $C D$, Mann KG: Activation/inactivation of human factor $V$ by plasmin. Blood 1989, 73:185-190.

16. Nogami K, Shima M, Matsumoto T, Nishiya K, Tanaka I, Yoshioka A: Mechanisms of plasmin-catalyzed inactivation of factor VIII: a crucial role for proteolytic cleavage at Arg336 responsible for plasmin-catalyzed factor VIII inactivation. J Bio/ Chem 2007, 282:5287-5295.

17. Li A, Wun TC: Proteolysis of tissue factor pathway inhibitor (TFPI) by plasmin: effect on TFPI activity. Thromb Haemost 1998, 80:423-427.

18. Stalboerger PG, Panetta CJ, Simari RD, Caplice NM: Plasmin proteolysis of endothelial cell and vessel wall associated tissue factor pathway inhibitor. Thromb Haemost 2001, 86:923-928.

19. Devereaux PJ, Goldman L, Cook DJ, Gilbert K, Leslie K, Guyatt GH: Perioperative cardiac events in patients undergoing noncardiac surgery: a review of the magnitude of the problem, the pathophysiology of the events and methods to estimate and communicate risk. CMAJ 2005 173:627-634.

doi:10.1186/cc11374

Cite this article as: Godier A, et al:: Tranexamic acid: less bleeding and less thrombosis? Critical Care 2012, 16:135. 